Corrigendum

\title{
Corrigendum to "Assessment of Toxicity and Therapeutic Effects of Goose Bone in a Rat Model"
}

\author{
Md. Yousuf Ali $\mathbb{D}^{1},{ }^{1}$ Alamgir Kabir, ${ }^{1}$ Shahad Saif Khandker, ${ }^{1}$ Tareq Hossan, \\ Md. Salman Shakil, ${ }^{1}$ Md. Aminul Islam ${ }^{D},{ }^{1}$ Md. Ashraful Hasan, ${ }^{1}$ Md. Sakib Hossen (D), \\ Siew Hua Gan $\mathbb{D}^{2}$, and Md. Ibrahim Khalil $\mathbb{D D}^{1}$ \\ ${ }^{1}$ Laboratory of Preventive and Integrative Biomedicine, Department of Biochemistry and Molecular Biology, \\ Jahangirnagar University, Savar, Dhaka 1342, Bangladesh \\ ${ }^{2}$ School of Pharmacy, Monash University Malaysia, Jalan Lagoon Selatan, 47500 Bandar Sunway, Subang Jaya, \\ Selangor, Malaysia
}

Correspondence should be addressed to Siew Hua Gan; gan.siewhua@monash.edu and Md. Ibrahim Khalil; drmikhalil@gmail.com Received 14 July 2020; Accepted 21 July 2020; Published 23 November 2020

Copyright $\odot 2020 \mathrm{Md}$. Yousuf Ali et al. This is an open access article distributed under the Creative Commons Attribution License, which permits unrestricted use, distribution, and reproduction in any medium, provided the original work is properly cited.

In the article titled "Assessment of toxicity and therapeutic effects of goose bone in a rat model" [1], the authors should have declared an additional conflict of interest as follows: Siew Hua Gan was the principal consultant (unpaid) to Star Goose Enterprise (KT 0406650-X) on research and development of goose bone natural product in the treatment of various diseases (9th Oct 2017-1st Jan 2020).

\section{References}

[1] M. Y. Ali, A. Kabir, S. S. Khandker et al., "Assessment of toxicity and therapeutic effects of goose bone in a rat model," Journal of Chemistry, vol. 2019, Article ID 1943601, 10 pages, 2019. 